\title{
ADGRG1 wt Allele
}

National Cancer Institute

\section{Source}

National Cancer Institute. ADGRG1 wt Allele. NCI Thesaurus. Code C99658.

Human ADGRG1 wild-type allele is located in the vicinity of $16 q 13$ and is approximately 45 kb in length. This allele, which encodes adhesion G-protein coupled receptor G1 protein, plays a role in both cell-cell signaling and brain development. Mutation of the gene is associated with bilateral frontoparietal polymicrogyria. 